\title{
RC-RNase-induced cell death in estrogen receptor positive breast tumors through down-regulation of Bcl-2 and estrogen receptor
}

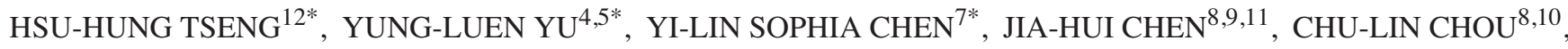 \\ TSUN-YUNG KUO ${ }^{7}$, JAANG-JIUN WANG ${ }^{6}$, MING-CHIEH LEE ${ }^{6}$, TING-HAN HUANG ${ }^{3}$, \\ MARK HUNG-CHIH CHEN ${ }^{2}$ and GIOU-TENG YIANG ${ }^{1}$ \\ ${ }^{1}$ Department of Emergency Medicine, Buddhist Tzu-Chi University and General Hospital, Hualien and Taipei Branch; \\ ${ }^{2}$ Bioluminescence in Life-image Laboratory, Department of Biotechnology, Research Institute of Biotechnology; \\ ${ }^{3}$ Institute of Clinical Nutrition, College of Medicines and Nursings, Hungkuang University, No. 34, Chung-Chie Road, \\ Shalu, Taichung 433; ${ }^{4}$ Graduate Institute of Cancer Biology and Center for Molecular Medicine, China Medical \\ University and Hospital; ${ }^{5}$ Department of Biotechnology, Asia University, Taichung, Taiwan; ${ }^{6}$ Division of \\ Pediatric Infectious Diseases, Emory University School of Medicine, Atlanta, USA; ${ }^{7}$ Graduate Institute of \\ Biotechnology, National Ilan University, Ilan; ${ }^{8}$ Graduate Institute of Clinical Medicine, \\ Tzu Chi University; ${ }^{9}$ Department of Surgery, ${ }^{10}$ Division of Nephrology, Hualien Armed \\ Forces General Hospital, Hualien; ${ }^{11}$ Division of General Surgery, Department of \\ Surgery, Tri-Service General Hospital, National Defense Medical Center, Taipei; \\ ${ }^{12}$ Division of General Surgery, Show Chwan Memorial Hospital, Changhua, Taiwan, R.O.C.
}

Received October 1, 2010; Accepted November 17, 2010

DOI: $10.3892 /$ or.2010.1114

\begin{abstract}
RC-RNase exerts anti-cancer effects on many tumors. However, the mechanisms by which RC-RNase induces cytotoxicity in different tumor cells are unclear. Currently, estrogen receptor (ER)-positive and negative breast tumors are treated with RC-RNase. Our data demonstrate that RC-RNase induces cell death on ER-positive but not on ERnegative breast tumors. This study also shows that downregulation of ER and $\mathrm{Bcl}-2$ is found on RC-RNase-treated ER-positive breast tumors. Additionally, Bcl-2 ovexpression can prevent ER-positive breast tumors from cell death treated with RC-RNase. In summary, this study demonstrates that
\end{abstract}

Correspondence to: Dr Giou-Teng Yiang, Department of Emergency Medicine, Buddhist Tzu-Chi University and General Hospital, Hualien and Taipei Branch, Taiwan, R.O.C.

E-mail: jtyiang@ms73.hinet.net

Dr Mark Hung-Chih Chen, Bioluminescence in Life-image Laboratory, Department of Biotechnology, Research Institute of Biotechnology, Hungkuang University, Shalu, Taichung 433, Taiwan, R.O.C

E-mail: blackfish@sunrise.hk.edu.tw

*Contributed equally

Abbreviations: XTT, sodium 3'-[1-(phenylamino-carbonyl)-3,4tetrazolium]-bis(4-methoxy-6-nitro) benzene sulfonic acid hydrate; RC-RNase, Rana catesbeiana ribonuclease; ER, estrogen receptor

Key words: estrogen receptor, Bcl-2, breast tumor
RC-RNase-induced cell death of ER-positive breast tumors is through regulation of ER and $\mathrm{Bcl}-2$.

\section{Introduction}

The anti-cancer effects of RNases have been demonstrated in several studies (1-3). Onconase, derived from Rana pipiens and RC-RNase from Rana catesbeiana both belong to the RNase family exerting anti-cancer activities (4-7). Presently, onconase has been used in the treatment of tumors in some clinical trails done in the USA and Europe (8-10). RC-RNase, with about $50 \%$ of its amino acid sequences homologous to that of onconase, exerts similar anti-cancer activities $(5,7,11)$. Many studies have demonstrated that onconase and RCRNase can induce cell death on many tumor cells $(5,7,11-13)$. However, the mechanisms of RNase-induced cytotoxicity and therapeutic target have remained unclear.

Our previous study has demonstrated that RC-RNases can induce different cytotoxicity on different tumor cells in humans and showed that RC-RNase induces cell death on breast tumors, hepatic tumors and leukemia through different caspase pathways (11). Additionally, many studies have also demonstrated that the degree of cytotoxicity induced by $\mathrm{RC}-\mathrm{RNase}$ correlates with the stages of differentiation of tumor cells $(6,14,15)$. These studies indicated that RC-RNase strongly exerts its anti-cancer activity on poorly-differentiated tumors, however, exerts a much lower activity on those tumors that are well-differentiated. However, the site where the RC-RNase will target the tumor cells to exert its cytotoxic effect is still unclear.

In this study, our primary data showed that RC-RNase can induce cytotoxicity on MCF-7 and ZR-75-1 breast 
tumors but cytotoxicity was not inducted on MDA-MB-231 and ZR-75-30 containing tumors. This result indicated that RC-RNase can induce different cytotoxicity on breast tumors depending on its receptors. Therefore, MCF-7, MDA-MB231, ZR-75-1 and ZR-75-30 containing breast tumors are widely used to study the target sites of RC-RNase activity on breast tumors.

Many reports have shown that ER-positive breast tumors have MCF-7 and ZR-75-1 (16-19) while ER-negative tumors have MDA-MB-231 and ZR-75-30 (20-22). Primarily, data presented in this report show that RC-RNase induces cell death on MCF-7 and ZR-75-1 tumors, but not on MDA-MB231 and ZR-75-30 tumors. That is, RC-RNase only induces cell death on ER-positive breast tumors. We further study estrogen receptor level on RC-RNase-treated ER-positive breast tumors. Our data showed that RC-RNase can induce down-regulation of ER. Therefore, ER is an important target of RC-RNase-induced cytotoxicity on ER-positive breast tumors. In addition, our data showed that down-regulation of Bcl-2 was found on RC-RNase-treated ER-positive breast tumors. Previous studies indicated that Bcl-2 and Bcl-XL belong to $\mathrm{Bcl}-2$ family and demonstrated that overexpression of Bcl-2 or Bcl-XL has anti-apoptosis effects (23-26). However, our previous study demonstrated that overexpression of Bcl-XL can not inhibit RC-RNase-induced cytotoxicity on ER-positive breast tumors (5). We investigated whether Bcl-2 can inhibit RC-RNase-induced cytotoxicity. Our study showed that overexpression of Bcl-2 can inhibit RC-RNase-inudced cytotoxicity on ER-positive breast tumors. Overall, we firstly demonstrated that RC-RNase induces cytotoxicity on ER-positive breast tumors, but not on ER-negative breast tumors through ER and Bcl-2 downregulation.

\section{Materials and methods}

Reagents and cell culture. RC-RNase was purified with the modified methods described in previous studies $(5,6,11)$. Ac-DEVD-pNA (Acetyl-Asp-Glu-Val-Asp-p-nitroanilide) was purchased from Anaspec (San Jose, CA). XTT assay kit was procured from Roche (Mannheim, Germany). Bcl-2 antibody was purchased from Upstate. ER and actin antibodies were commissioned from Pharmingen Laboratories (San Diego, CA), and Chemicon Laboratories (Temecula, CA), respectively. Dr Shun-Yuan Jiang (Tzu Chi General Hospital) provided the human breast carcinoma cells with MCF-7, MDA-MB-231, ZR-75-1 and ZR-75-30 and cultures were made using Dulbecco's Modified Eagle Medium (Gibco BRL) supple-mented with $10 \%$-heat-inactivated-fetal-bovine serum (Hyclone ${ }^{\circledR}$ Laboratories, Inc., Logan, UT), 2 mM Lglutamine (Gibco BRL), $100 \mathrm{IU} / \mathrm{ml}$ penicillin $\mathrm{G}$ sodium (Gibco BRL), $100 \mu \mathrm{g} / \mathrm{ml}$ streptomycin sulfate (Gibco BRL), $1 \mathrm{mM}$ sodium pyruvate (Sigma Chemical Co., St. Louis, MO) and 0.1 mM non-essential amino acids (Gibco BRL).

Survival rate assay. Cell survival rate was determined using XTT \{sodium 3'-[1-(phenylamino-carbonyl)-3,4-tetrazolium]bis(4-methoxy-6-nitro) benzene sulfonic acid hydrate $\}$ kit which analyzes the activity of mitochondrial dehydrogenase. Briefly, 2x103-cells were grown in each well of 96-well- containing cell culture plates overnight. The following day, these cells were treated with RC-RNase. XTT assays were carefully performed every $24 \mathrm{~h}$ following instructions from the manufacturer. Absorbance was determined at $492 \mathrm{~nm}$ using a multi-well ELISA reader (Molecular Devices, Sunnyvale, CA).

Caspase activity assay. Cells were treated with the lytic buffer (50 mM Tris-HCl, $120 \mathrm{mM} \mathrm{NaCl}, 1 \mathrm{mM}$ EDTA, $1 \%$ NP-40, pH 7.5) supplemented with protease inhibitors. Cell pellets were removed via centrifugation at $15000 \mathrm{x}$ g for $20 \mathrm{~min}$ at $4^{\circ} \mathrm{C}$. The caspase activity assay was determined in a reaction solution containing $40 \mu \mathrm{l}$ cell lysates ( $80 \mu \mathrm{g}$ total protein), $158 \mu 1$ of reaction buffer (20\% glycerol, $0.5 \mathrm{mM}$ EDTA, $5 \mathrm{mM}$ dithiothreitol, $100 \mathrm{mM}$ HEPES, $\mathrm{pH} 7.5$ ) and $2 \mu \mathrm{l}$ of fluorogenic Ac-DEVD-pNA and was incubated at $37^{\circ} \mathrm{C}$ for $6 \mathrm{~h}$. The fluorogenic substrate cleavage readout was the pnitroanilide release as detected at $405 \mathrm{~nm}$ in an ultra-microplate reader (Bio-Tek instruments).

Western blot analysis. Cells were collected using cell scrapers and lysed in RIPA buffer (10 mM Tris-base, $\mathrm{pH} 7.4,150 \mathrm{mM}$ $\mathrm{NaCl}, 1 \% \mathrm{NP}-40,0.5 \%$ sodium deoxycholate, $0.1 \%$ SDS) containing protease inhibitors (Calbiochem, La Jolla, CA). Equal amounts of the total proteins were loaded into a $13.3 \%$ SDS-polyacrylamide gel and underwent electrophoresis. They were then transferred to a polyvinyldene difluoride membrane (Amersham Pharmacia Biotech). The membranes were blocked with 5\% skim milk and 1\% NP-40 in TBS-T $(0.8 \% \mathrm{NaCl}, 0.02 \% \mathrm{KCl}, 25 \mathrm{mM}$ Tris- $\mathrm{HCl}, 0.05 \%$ Tween-20, at $\mathrm{pH} 7.4$ ) for $1 \mathrm{~h}$, incubated with the primary antibody (1:500 dilution in the blocking buffer) at $4^{\circ} \mathrm{C}$ overnight, and subsequent incubation was done with biotinylated anti-mouse or anti-rabbit IgG (1:1000 or 1:10000 dilution in the blocking buffer) and streptavidin-horseradish peroxidase conjugates (1:2000 dilution in PBS). The membranes were developed using the Super Signal ${ }^{\mathrm{TM}}$ chemiluminescent-HRP substrate system (Pierce, Rockford, IL).

Establishment of transfectants overexpressing Bcl-2 and $B c l-X L$. Human Bcl-2/PCR 3.1 and Bcl-XL/PCR 3.1 plasmids were constructed employing methods as mentioned previously (5). MCF-7 cells were transfected with Bcl-2/PCR 3.1 or Bcl-XL/PCR 3.1 plasmids using lipofectamine (Gibco) and selected by $400 \mu \mathrm{g} / \mathrm{ml}$ geneticin (Gibco). These transfectants were cultured in the 96-well plates to make a single cell per well. After a single cell became confluent, they were transferred to 25-T flasks and cultured with complete medium using $400 \mu \mathrm{g} / \mathrm{ml}$ geneticin. Transfectants overexpressing Bcl-2 and Bcl-XL were determined using the Western blot method.

\section{Results}

$R C$-RNase induces cytotoxicity and caspase-3-like activity on $M C F-7$ and ZR-75-1 breast tumors. The following observations were made and recorded in the course of this study. The survival rate of MCF-7 and ZR-75-1 breast tumor cells was below $50 \%$, noted on day 3 after treatment with RCRNase while $>80 \%$ of MDA-MB-231 and ZR-75-30 breast 

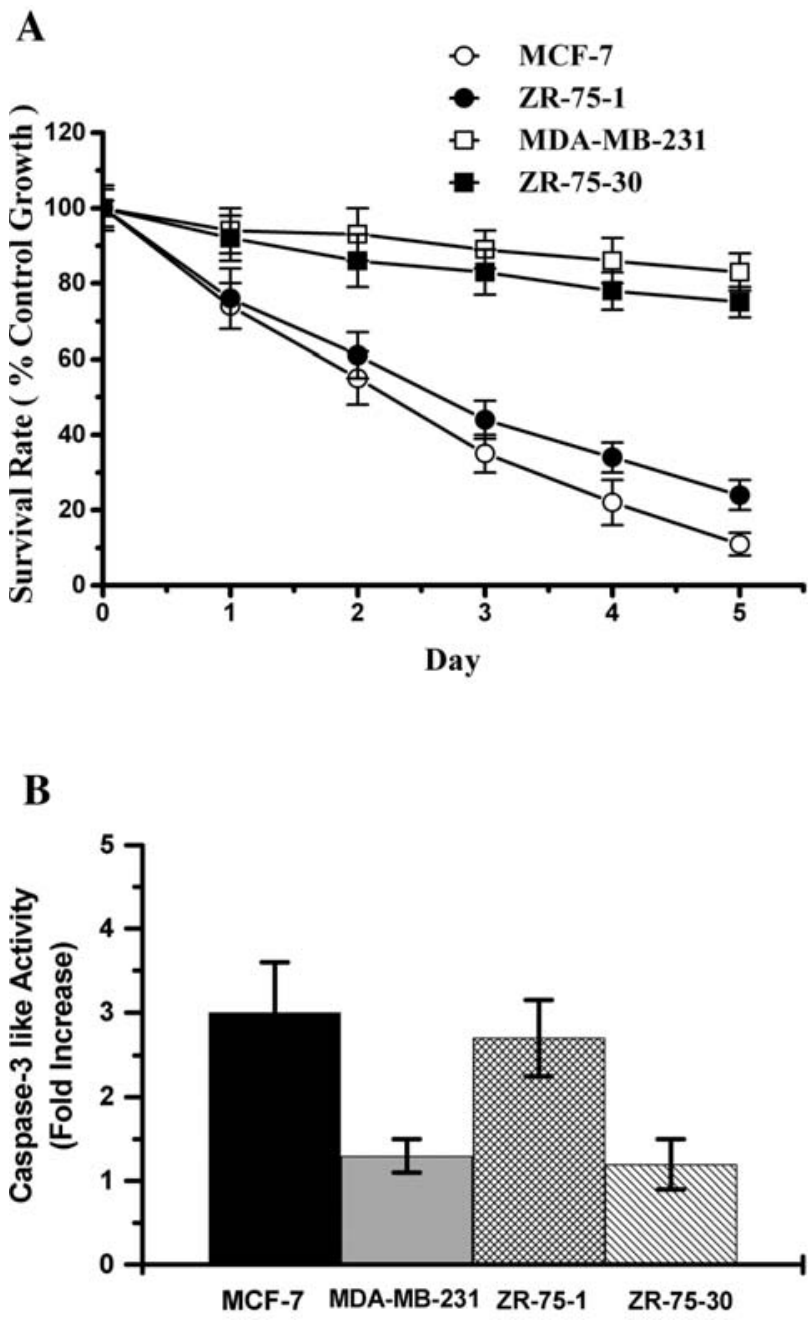

Figure 1. Survival rate and caspase-3-like activity. The survival rates of the 4 indicated breast tumor cells were treated with $20 \mu \mathrm{g} / \mathrm{ml}$ for 4 days (A). The caspase-3 like activities of the indicated cells were treated with $20 \mu \mathrm{g} / \mathrm{ml}$ at day 3 (B). Data were obtained from three independent triplicate experiments and presented as the mean $\pm \mathrm{SD}$.

tumor cells survived after treatment with RC-RNase (Fig. 1A). The data indicated that RC-RNase induces cytotoxicity on MCF-7 and ZR-75-1 breast tumor cells. However, RCRNase induces lesser cytotoxicity on MDA-MB-231 and ZR75-30 tumor cells. Caspase-3 like activity was also tested in this study. The result showed that RC-RNase induces caspase-3-like activity on MCF-7 and ZR-75-1 breast tumor cells with no activity observed on MDA-MB-231 and ZR75-30 tumor cells (Fig. 1B). These observations are highly suggestive of RC-RNase ability to induce cytotoxicity on MCF-7 and ZR-75-1 breast tumor cells through the caspase pathway.

Down-regulation of estrogen receptor and Bcl-2 on ERpositive breast tumors with $R C$-RNase treatment. MCF-7 and ZR-75-1 cells are ER-positive breast tumor cells. They cannot survive without estrogen. However, MDA-MB-231 and ZR-75-30 cells are ER-negative breast tumor cells and can survive without estrogen. As shown in Fig. 1A, RC-RNase induce cytotoxicity and caspase-3 like activity on MCF-7 and ZR-75-1 breast tumor cells but not on MDA-MB-231 and

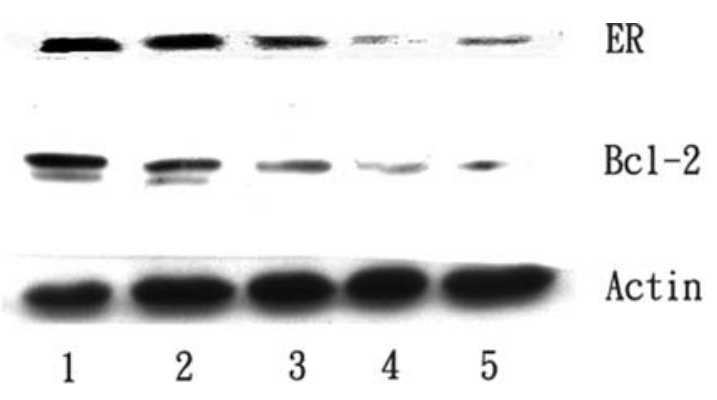

Figure 2. Down-regulation of estrogen receptor (ER) and Bcl-2 was analyzed by Western blot analysis on MCF-7 breast tumor cells. Cells were treated with $0 \mu \mathrm{g} / \mathrm{ml}$ (lane 1), $5 \mu \mathrm{g} / \mathrm{ml}$ (lane 2), $10 \mu \mathrm{g} / \mathrm{ml}$ (lane 3), $20 \mu \mathrm{g} / \mathrm{ml}$ (lane 4) and $40 \mu \mathrm{g} / \mathrm{ml} \mathrm{RC-RNase} \mathrm{(lane} \mathrm{5)} \mathrm{for} 3$ days.
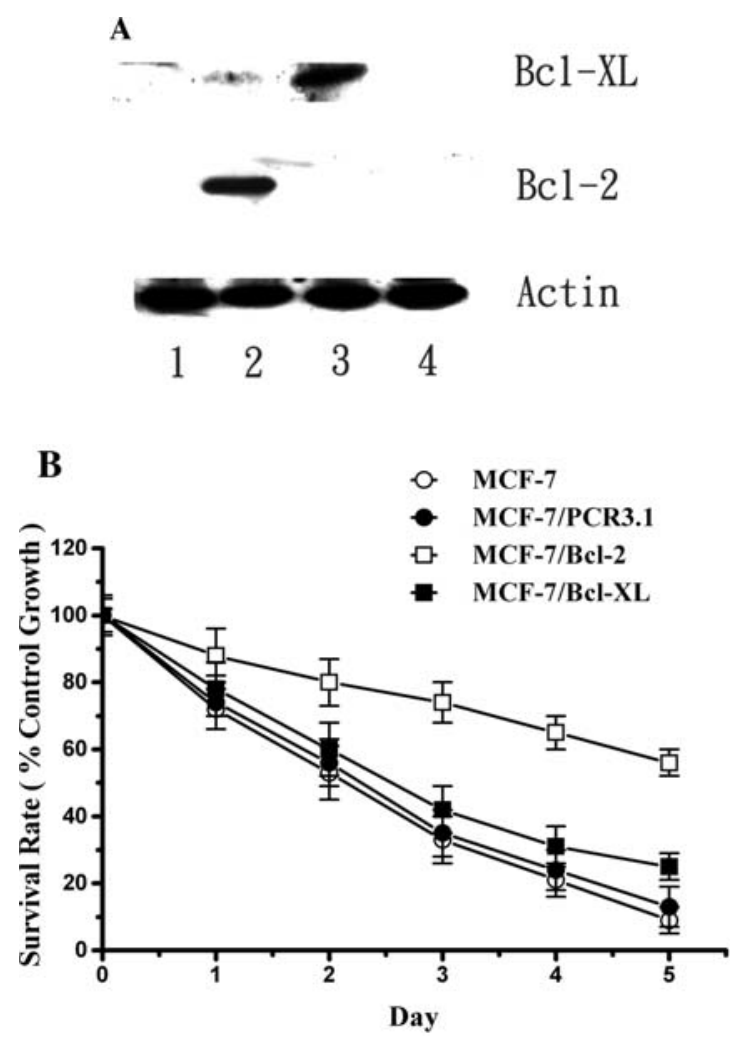

Figure 3. Transfectants and the survival rates. Transfectants (MCF-7, lane 1; MCF-7/Bcl-2, lane 2; MCF-7/Bcl-XL, lane 3; MCF-7/PCR 3.1, lane 4) with related-overexpresion proteins were checked by Western blot analysis (A). The survival rates of these cells with RC-RNase treatments for 5 days (B). Data were obtained from three independent triplicate experiments and presented as the mean \pm SD.

ZR-75-30 breast tumor cells. That is, RC-RNase has a stronger cytotoxicity on ER-positive breast tumor cells than ERnegative breast tumor cells. This result indicates that ER may be one of targets on RC-RNase-treated ER-positive breast tumors. To demonstrate this idea, ER was determined by Western blotting. Our result showed that degradation of ER can be found on RC-RNase-treated ER-positive breast tumor cells in a dose-dependent manner (Fig. 2). Additionally, degradation of Bcl-2 was found on RC-RNase-treated ERpositive breast tumor cells (Fig. 2). Based on the observations and results in this study, it is highly suggestive that RC- 


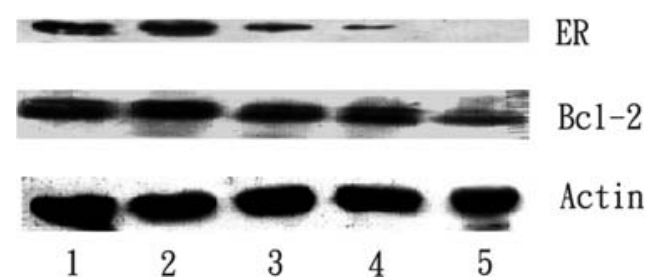

Figure 4. Down-regulation of ER and Bcl-2 was analyzed by Western blotting on MCF-7/Bcl-2 transfectants. Cells are treated for 3 days with RC-RNase $0 \mu \mathrm{g} / \mathrm{ml}$ (lane 1), $5 \mu \mathrm{g} / \mathrm{ml}$ (lane 2), $10 \mu \mathrm{g} / \mathrm{ml}$ (lane 3), $20 \mu \mathrm{g} / \mathrm{ml}$ (lane 4) and $40 \mu \mathrm{g} / \mathrm{ml}$ (lane 5).

RNase induces cytotoxicity on ER-positive breast tumor cells through down-regulation of ER and Bcl-2.

Overexpression of Bcl-2 inhibits RC-RNase-induced cytotoxicity on ER-positive breast tumors. Transfectants overexpressing Bcl-2 and Bcl-XL was selected successfully in this study. As shown in Fig. 3A, MCF-7/Bcl-2 transfectants can express Bcl-2 and MCF-7/Bcl-XL transfectants can express Bcl-XL. MCF-7 cells and MCF-7/PCR 3.1 transfectants were used as a negative control. The survival rates of MCF-7, MCF-7/Bcl-2, MCF-7/Bcl-XL and MCF-7/PCR 3.1 with RC-RNase treatment showed that only $\mathrm{MCF}-7 / \mathrm{Bcl}-2$ transfectants inhibited RC-RNase-induced cytotoxicity (Fig. 3B) while MCF-7/Bcl-XL transfectants did not (Fig. $3 \mathrm{~B})$. We can deduce from our study that only Bcl-2 can inhibit RC-RNase-induced cytotoxicity on MCF-7 cells despite $\mathrm{Bcl}-2$ and $\mathrm{Bcl}-\mathrm{XL}$ both belonging to the antiapoptosis protein family.

Overexpression of Bcl-2 inhibits down-regulation of Bcl-2. We further determined the expression of ER and Bcl-2 on RC-RNase-treated MCF-7/Bcl-2 transfectants. The result is shown in Fig. 4. Comparing with Fig. 2, down-regulation of Bcl-2 is clearer on RC-RNase-treated MCF-7 cells than RCRNase-treated MCF-7/Bcl-2 transfectants. Furthermore, our data indicate that down-regulation of ER was observed clearly on RC-RNase-treated MCF-7/Bcl-2 transfectants at day 3. This result is similar to that of ER down-regulation on RC-RNase-treated MCF-7 cells (Fig. 2).

\section{Discussion}

Data from previous literature demonstrated that RC-RNase can induce cytotoxicity on breast tumors (MCF-7 cells) through caspase-7 activation $(5,11)$. However, the target sites where RC-RNase will induce cytotoxicity on breast tumors are still unclear. In this study, our data showed that RCRNase induces cytotoxicity on ER-positive breast tumors (MCF-7 and ZR-75-1) but fails to induce cytotoxicity on ERnegative breast tumors (MDA-MB-231 and ZR-75-30). In other words, RC-RNase has an anti-cancer effect only on ER-positive breast tumors. Additionally, our study demonstrates that RC-RNase can induce down-regulation of ER on ER-positive breast tumors. ER-positive breast tumor treatments have demonstrated that cell proliferation can be inhibited on ER-positive breast tumors by blocking the ER signal pathway (27-30). Based on these studies and our results, we suggest that ER is an important target of RCRNase-induced cytotoxity on ER-positive breast tumors.

Bcl-2 with anti-apoptotic functions and survival effects have also been demonstrated in some studies (31-33). These studies indicated that various cell types cannot survive when Bcl-2 level decreased. Our study shows that down-regulation of Bcl-2 is expressed on ER-positive breast tumors treated with RC-RNase. Many studies have demonstrated that downregulation of $\mathrm{Bcl}-2$ can induce cell death on ER-positive breast tumors (34-36). These results are similar to our study. We therefore consider that Bcl-2 is also a target site of action for RC-RNase to induce cytotoxity on ER-positive breast tumors. Our study demonstrates that RC-RNase can downregulate ER and Bcl-2 levels resulting in cell death on ERpositive breast tumors.

Various reports have indicated that Bcl-2 and Bcl-XL are anti-apoptotic factors (23-26). These reports suggested that overexpression of Bcl-2 and Bcl-XL can inhibit cell death and the down-regulation of Bcl-2 and Bcl-XL can induce cell death. However, previous studies demonstrated that Bcl-2 overexpression cannot prevent hyperoxia-induced cell death on epithelial cells (37) and Bcl-XL overexpression cannot inhibit apoptosis on hepatocytes (38). Additionally, it has been reported that $\mathrm{Bcl}-2$ and $\mathrm{Bcl}-\mathrm{XL}$ inhibit cell death in a different manner (39). These studies indicated that antiapoptotic effects between $\mathrm{Bcl}-2$ and $\mathrm{Bcl}-\mathrm{XL}$ on different cells vary depending on the target site of action and cellular function (37-40). In this study, our results demonstrate that Bcl-XL overexpression can not inhibit RC-RNase-induced cytotoxicity on MCF-7 cells. This result is similar with our previous study (5). Furthermore, our study shows that Bcl-2 overexpression can inhibit RC-RNase-induced cytotoxicity on ER-positive breast tumors indicating that the antiapoptotic effect on RC-RNase-treated ER-positive breast tumors is dependent on $\mathrm{Bcl}-2$ functions but not on $\mathrm{Bcl}-\mathrm{XL}$ functions.

In summary, this study is able to demonstrate that RCRNase induces cell death on ER-positive breast tumors but not on ER-negative breast tumors through down-regulation of ER and Bcl-2. In addition, the anti-cancer effect on RCRNase-treated ER-positive breast tumors is related to $\mathrm{Bcl}-2$ overexpression, but not to Bcl-XL overexpression.

\section{Acknowledgements}

This study was supported by the grants from Tzu Chi General Hospital of Taiwan and by the National Science Council of Taiwan grant, NSC95-2320-B-241-007 to C.W.W. and was partially supported by the National Science Council of Taiwan grants, NSC 97-2313-B-241-001-MY3 to M.H.C.C.

\section{References}

1. Shlyakhovenko VA: Ribonucleases in tumor growth. Exp Oncol 31: 127-133, 2009.

2. Ardelt W, Ardelt B and Darzynkiewicz Z: Ribonucleases as potential modalities in anticancer therapy. Eur J Pharmacol 625: 181-189, 2009.

3. Arnold U and Ulbrich-Hofmann R: Natural and engineered ribonucleases as potential cancer therapeutics. Biotechnol Lett 28: 1615-1622, 2006. 
4. Ardelt W, Mikulski SM and Shogen K: Amino acid sequence of an anti-tumor protein from Rana pipiens oocytes and early embryos. Homology to pancreatic ribonucleases. J Biol Chem 266: 245-251, 1991

5. $\mathrm{Hu} \mathrm{CC}$, Tang $\mathrm{CH}$ and Wang JJ: Caspase activation in response to cytotoxic Rana catesbeiana ribonuclease in MCF-7 cells FEBS Lett 503: 65-68, 2001

6. Wei CW, Hu CC, Tang CH, Lee MC and Wang JJ: Induction of differentiation rescues HL-60 cells from Rana catesbeiana ribonuclease-induced cell death. FEBS Lett 531: 421-426, 2002.

7. Ardelt W, Shogen K and Darzynkiewicz Z: Onconase and amphinase, the antitumor ribonucleases from Rana pipiens oocytes. Curr Pharm Biotechnol 9: 215-225, 2008.

8. Mikulski SM, Costanzi JJ, Vogelzang NJ, et al: Phase II trial of a single weekly intravenous dose of ranpirnase in patients with unresectable malignant mesothelioma. J Clin Oncol 20: 274-281, 2002

9. Favaretto A: Overview on ongoing or planned clinical trials in Europe. Lung Cancer 49 (Suppl. 1): S117-S121, 2005.

10. Ita M, Halicka HD, Tanaka T, et al: Remarkable enhancement of cytotoxicity of onconase and cepharanthine when used in combination on various tumor cell lines. Cancer Biol Ther 7: 1104-1108, 2008.

11. Tang CH, Hu CC, Wei CW and Wang JJ: Synergism of Rana catesbeiana ribonuclease and IFN-gamma triggers distinct death machineries in different human cancer cells. FEBS Lett 579: 265-270, 2005 .

12. Halicka DH, Pozarowski P, Ita M, et al: Enhancement of activation-induced apoptosis of lymphocytes by the cytotoxic ribonuclease onconase (Ranpirnase). Int J Oncol 21: 1245-1250, 2002.

13. Halicka HD, Ardelt B, Shogen K and Darzynkiewicz Z: Mild hyperthermia predisposes tumor cells to undergo apoptosis upon treatment with onconase. Int J Oncol 30: 841-847, 2007.

14. Hu CC, Lee YH, Tang CH, Cheng JT and Wang JJ: Synergistic cytotoxicity of Rana catesbeiana ribonuclease and IFN-gamma on hepatoma cells. Biochem Biophys Res Commun 280 : 1229-1236, 2001.

15. Yiang GT, Yu YL, Hu SC, Chen MH, Wang JJ and Wei CW: $\mathrm{PKC}$ and $\mathrm{MEK}$ pathways inhibit caspase-9/-3-mediated cytotoxicity in differentiated cells. FEBS Lett 582: 881-885, 2008

16. Saggar JK, Chen J, Corey P and Thompson LU: Dietary flaxseed lignan or oil combined with tamoxifen treatment affects MCF-7 tumor growth through estrogen receptor- and growth factorsignaling pathways. Mol Nutr Food Res 54: 415-425, 2010.

17. Adams BD, Cowee DM and White BA: The role of miR-206 in the epidermal growth factor (EGF) induced repression of estrogen receptor-alpha (ERalpha) signaling and a luminal phenotype in MCF-7 breast cancer cells. Mol Endocrinol 23 : 1215-1230, 2009.

18. Sasser AK, Sullivan NJ, Studebaker AW, Hendey LF, Axel AE and Hall BM: Interleukin-6 is a potent growth factor for ERalpha-positive human breast cancer. FASEB J 21: 3763-3770, 2007.

19. Sawatsri S, Samid D, Malkapuram S and Sidell N: Inhibition of estrogen-dependent breast cell responses with phenylacetate. Int J Cancer 93: 687-692, 2001.

20. Tao J, Zhang P, Liu G, et al: Cytotoxicity of Chinese motherwort (YiMuCao) aqueous ethanol extract is non-apoptotic and estrogen receptor independent on human breast cancer cells. J Ethnopharmacol 122: 234-239, 2009.

21. Shyu RY, Chang SC, Yu JC, et al: Expression and regulation of retinoid-inducible gene 1 (RIG1) in breast cancer. Anticancer Res 25: 2453-2460, 2005.
22. Prakash P, Russell RM and Krinsky NI: In vitro inhibition of proliferation of estrogen-dependent and estrogen-independent human breast cancer cells treated with carotenoids or retinoids. J Nutr 131: 1574-1580, 2001.

23. Sot B, Freund SM and Fersht AR: Comparative biophysical characterization of p53 with the pro-apoptotic BAK and the anti-apoptotic BCL-xL. J Biol Chem 282: 29193-29200, 2007.

24. Kuo CC, Liang SM and Liang CM: CpG-B oligodeoxynucleotide promotes cell survival via up-regulation of Hsp70 to increase $\mathrm{Bcl}-\mathrm{xL}$ and to decrease apoptosis-inducing factor translocation. J Biol Chem 281: 38200-38207, 2006.

25. Janumyan YM, Sansam CG, Chattopadhyay A, et al: Bcl-xL/ Bcl-2 coordinately regulates apoptosis, cell cycle arrest and cell cycle entry. EMBO J 22: 5459-5470, 2003.

26. Park JW, Choi YJ, Suh SI, et al: Bcl-2 overexpression attenuates resveratrol-induced apoptosis in U937 cells by inhibition of caspase-3 activity. Carcinogenesis 22: 1633-1639, 2001.

27. Lee SH and Nam HS: TNF alpha-induced down-regulation of estrogen receptor alpha in MCF-7 breast cancer cells. Mol Cell 26: 285-290, 2008

28. Sartippour MR, Pietras R, Marquez-Garban DC, et al: The combination of green tea and tamoxifen is effective against breast cancer. Carcinogenesis 27: 2424-2433, 2006.

29. Hua KT, Way TD and Lin JK: Pentagalloylglucose inhibits estrogen receptor alpha by lysosome-dependent depletion and modulates ErbB/PI3K/Akt pathway in human breast cancer MCF-7 cells. Mol Carcinog 45: 551-560, 2006.

30. Martin LA, Pancholi S, Chan CM, et al: The anti-oestrogen ICI 182,780 , but not tamoxifen, inhibits the growth of MCF-7 breast cancer cells refractory to long-term oestrogen deprivation through down-regulation of oestrogen receptor and IGF signalling. Endocr Relat Cancer 12: 1017-1036, 2005.

31. Kren L, Brazdil J, Hermanova M, et al: Prognostic significance of anti-apoptosis proteins survivin and bcl-2 in non-small cell lung carcinomas: a clinicopathologic study of 102 cases. Appl Immunohistochem Mol Morphol 12: 44-49, 2004.

32. De Graaf AO, Meijerink JP, van den Heuvel LP, et al: Bcl-2 protects against apoptosis induced by antimycin A and bongkrekic acid without restoring cellular ATP levels. Biochim Biophys Acta 1554: 57-65, 2002

33. Hawkins CJ and Vaux DL: Analysis of the role of bcl-2 in apoptosis. Immunol Rev 142: 127-139, 1994.

34. Yu JS and Kim AK: Platycodin D induces apoptosis in MCF-7 human breast cancer cells. J Med Food 13: 298-305, 2010.

35. Li B, Chu X, Gao M and Li W: Apoptotic mechanism of MCF-7 breast cells in vivo and in vitro induced by photodynamic therapy with C-phycocyanin. Acta Biochim Biophys Sin (Shanghai) 42: 80-89, 2010.

36. Ferenc P, Solar P, Kleban J, Mikes J and Fedorocko P: Downregulation of $\mathrm{Bcl}-2$ and Akt induced by combination of photoactivated hypericin and genistein in human breast cancer cells. J Photochem Photobiol B 98: 25-34, 2010.

37. Metrailler-Ruchonnet I, Pagano A, Carnesecchi S, et al: Bcl-2 overexpression in type II epithelial cells does not prevent hyperoxia-induced acute lung injury in mice. Am J Physiol Lung Cell Mol Physiol 299: L312-L322, 2010.

38. Hatano E: Tumor necrosis factor signaling in hepatocyte apoptosis. J Gastroenterol Hepatol 22 (Suppl. 1): S43-S44, 2007.

39. Kim R: Unknotting the roles of Bcl-2 and Bcl-xL in cell death. Biochem Biophys Res Commun 333: 336-343, 2005.

40. Yu YL, Chiang YJ, Chen YC, et al: MAPK-mediated phosphorylation of GATA-1 promotes Bcl-XL expression and cell survival. J Biol Chem 280: 29533-29542, 2005. 